\title{
E-BRIEF
}

August 13, 2014

MONETARY POLICY

\section{Money Still Matters: How the Bank of Canada Might Better Monitor Inflation}

by

Mati Dubrovinsky

- The Bank of Canada was successful in stabilizing inflation around its 2 percent target in the decade from 1997 to 2008, before the recent financial crisis.

- The strong association between the growth of the money supply and inflation during the period 1997 to 2008 - when inflation was at its target - indicates the importance of monitoring the growth of monetary aggregates.

- Notwithstanding a recent increase, inflation largely has been below target since 2012. The association between money growth and inflation has been weak since 2008, as it was in the decade before 1997. This is likely due to unpredictable changes in the velocity of money in Canada during the 1980s, and since the recent recession.

- If inflation expectations remain near the target, the Bank of Canada need not act drastically. However, the Bank should monitor monetary aggregates carefully, and dedicate more attention to an array of measures for inflation expectations.

- If expectations fall below target, the Bank should pursue more aggressive expansionary monetary policy.

A major goal for monetary policy is maintaining low and predictable inflation. Most economists agree that this condition is vital for a growing economy, and limits crises and downturns in the long run. The Bank of Canada (BoC) has managed to ensure with reasonable success, since 1995, that the prices of all goods and services have risen by about 2 percent a year - in line with the 2 percent inflation target.

I am grateful for fruitful conversations with Steve Ambler, David Laidler, Finn Poschmann and Bill

Robson. All errors are my own. 
Firms and individual consumers, however, base their decisions on future inflation. Since future inflation is not known with certainty, they rely on expected inflation. Expectations, of course, are affected by past and present actual inflation. From mid-2012 and until recently, the rate of inflation was largely below 2 percent and often below its lower bound of 1 percent. ${ }^{1}$ In June 2014, year-on-year Consumer Price Index (CPI ) inflation stood at 2.3 percent, and core inflation was at 1.7 percent. The $\mathrm{BoC}$ views this increase in inflation above target as transitory, and predicts that inflation is likely to fall below target in 2015 (Poloz 2014). While inflation expectations appear well-anchored at 2 percent today, if the low inflation trend continues, there is a danger that expected inflation will fall as well.

Inflation below expectations for a prolonged period hurts the economy for a number of reasons. Usually interest rates on loans adjust to reflect inflation expectations. The principal borrowed, however, depreciates more slowly than anticipated when inflation is below expectations, putting higher pressure on borrowers. Persistent inflation below expectations also lowers expectations. If negative inflation is expected - prices are anticipated to fall over time - individuals will hold off spending to benefit from lower prices in the future, which will slow growth.

This paper discusses the recent apparent decline in the effectiveness of monetary policy at keeping CPIinflation close to the middle range of the target band, and concludes that the BoC should pay particular attention to the possibility that the public's inflation expectations will shift below targeted inflation, and should be prepared to adjust policy if and when such a shift occurs.

\section{Monetary Policy and Inflation}

The mechanism through which monetary policy influences inflation in Canada can be summarized as follows. The BoC announces its target for the overnight rate. The central bank is willing to lend Canadian dollars overnight to commercial banks at a rate one-quarter of a percent higher than the announced target, and is willing to pay interest of one-quarter of a percent lower than the target on overnight deposits that commercial banks hold with it.

Commercial banks thus have an incentive to borrow and lend to one another at rates close to the overnight target, rather than dealing with the $\mathrm{BoC}$ directly. In this way, the $\mathrm{BoC}$ influences the costs of funds for banks. ${ }^{2}$

The next step in the chain unfolds when, based on their new costs of funds, commercial banks change the interest rate they are willing to pay on savings account balances, or charge on loans made to customers. These new commercial bank interest rates affect the financial portfolios Canadians hold. ${ }^{3}$

Most of us have some balance in our chequing account, a balance in our savings account, investments in financial assets, a number of loans, and some credit card balances. Decisions on what amount of our assets and

1 The target for inflation is a band, between 1 and 3 percent. The $\mathrm{BoC}$, however, tries to keep it as close as possible to the middle of the band - at 2 percent.

2 Currently, as part of settling payments between commercial banks, the $\mathrm{BoC}$ does not allow banks to hold non-zero account balances overnight. If banks do not have enough (or conversely hold a surplus of) funds by end of day, they must borrow (lend).

3 For those readers following the publications of the BoC, it may look odd that I describe the monetary transmission mechanism as portfolio adjustments. BoC's official document describes the transmission mechanism in terms of events on the real side of the economy (Bank of Canada 2012). Portfolio adjustments, however, are the financial representation of these real adjustments. 
liabilities we keep in each of these accounts depends on the interest rates our bank offers for savings balances and for loans. When interest rates go down, we tend to keep higher balances in non-interest bearing chequing accounts, and are more likely to take out new loans. If the savings account interest rate goes up, we prefer to increase our savings account balances at the expense of other accounts - such as risky financial assets, and noninterest bearing chequing accounts. Also, when loan rates are higher we are less likely to take out a new loan, and more likely to pay off outstanding loans faster. Firms make similar decisions. Thus, when our bank changes rates on saving and borrowing we react by shifting our portfolio holdings between money and other assets (Freedman 2000).

Through this portfolio rebalancing, monetary policy is transmitted to the economy at large. For households and businesses to make purchases of non-durable goods for everyday consumption, durable goods for investment or long-term consumption, physical structures, or other non-financial investments, they need "money" in the form of readily available, or liquid, payment instruments.

When the target for overnight rate goes down, money becomes more readily available in the economy through borrowing. This new money feeds to increased purchases in some sectors of the economy, including sectors which manufacture capital goods. ${ }^{4}$ Prices in these sectors will rise as a result of increased activity. As the higher revenue in the more active sectors spreads further through the economy, prices rise in other sectors as well. When the general price level persistently rises, we call it inflation. For this reason, when rates go down we first see a positive impact on GDP growth, and then we observe higher inflation (Laidler 1999).

\section{How Well Has Monetary Policy Worked in Recent Years?}

To examine how well monetary policy works we need to measure its impact on inflation. A given interest rate change, however, does not always cause the same size of portfolio adjustment. An additional complication is that we usually adjust our portfolios gradually, owing to the costs of adjusting (Laidler 1999). Trips to the bank and calls to customer service take valuable time. Additionally, banks charge fees for certain operations.

To overcome these difficulties in measuring the size of portfolio adjustment directly, I use a measure called the "money gap" (Laidler and Robson 1991). Over short time periods, such as one quarter, the inflation rate is largely predetermined by past conditions, and so is GDP. Nominal GDP, the sum of all goods and services multiplied by their current prices, is also predetermined. For this reason, nominal GDP - whose components are bought and sold - is an indicator of liquid asset balances in the public's portfolio before an overnight rate change induces a new adjustment. A useful measure of money, or payment balances, tallies the liquid asset balances in the public's portfolio after a policy rate change, and before they have had enough time to use it for additional purchases.

The money gap is the growth of money in the public's portfolio in excess of nominal GDP growth. The money gap predicts the future path of inflation - when the money gap is higher, so will be future inflation. When the money gap is lower, future inflation will be lower too. Thus, the money gap and future inflation would be positively correlated.

To examine the effectiveness of monetary policy, I correlate the money gap with subsequent inflation. To estimate the money gap, I subtract the growth rate of nominal GDP from the growth rate of money, as measured

4 When interest rates in Canada fall, fewer investors are willing to hold Canadian dollar denominated assets. This phenomenon causes depreciation of the exchange rate, and a rise in the prices of imported goods. The exchange rate is another mechanism that transmits monetary policy. 
by M1+. M1+ includes cash in circulation and chequing account balances at federally regulated banks and provincially regulated trust companies and credit unions. ${ }^{5}$ As a measure of inflation, I take the GDP deflator rather than CPI, as is common in the monetarist approach (Laidler and Robson 1991, Laidler 1999). CPI measures price increases for a bundle representative of typical household consumption in Canada, and some items in the bundle are imported. The GDP deflator measures price increases for the mix of goods and services produced in Canada. The two measures, however, are highly correlated.

The Bank of Canada (2012) argues that the time which lapses between the announcement of the BoC's overnight rate and its ultimate impact on inflation is six to eight quarters. This implies that the time lapse between a change in portfolio balances, or the money gap, and inflation is somewhat shorter. The first step of monetary policy transmission takes place when commercial banks change their rates, and only then the public adjusts its portfolio. Both of these operations take time.

A high positive correlation, therefore, between the money gap and inflation implies an effective monetary policy transmitted through the channel I discussed above. ${ }^{6,7}$ Figure 1 presents correlations between contemporary inflation and past money gaps at time lags of up to seven quarters.

The period between the fourth quarter of 1997 and the third quarter of 2008 (the middle bars in Figure 1) exhibits the expected pattern. The money gap is positively correlated with next year's inflation - five quarters into the future. This implies an effective transmission of monetary policy.

The period from 1982 until the third quarter of 1997 (the left side bars in Figure 1), however, does not exhibit the expected pattern. Similarly, since the recent recession in the fourth quarter of 2008 (the right side bars in Figure 1), the expected pattern of positive correlation between the money gap and inflation disappears again. Coincidentally, perhaps, it is during these two periods that the $\mathrm{BoC}$ had troubles controlling inflation. ${ }^{8}$

\section{Predictability of Velocity and Monetary Policy}

Higher variability of the money gap in the first and last periods, can explain the lower efficiency of monetary policy. ${ }^{9}$ The money gap is the negative of the growth rate of the velocity of money. The velocity of money is a concept that measures how many times a single unit of currency changes hands to buy current output - the ratio of nominal GDP to money balances. If velocity is constant, then a rise in the money balances will cause the price level to rise, thus generating inflation. If the velocity of money falls, however, the force pushing the price level upwards weakens. More money is created, but less is used in transactions.

5 The M1+ measure of the money gap exhibits a stronger statistical association with inflation, for the period I study, than do broader measures of money. Additionally, the key monetary policy lever, the overnight rate, influences in an intuitive way only the narrower measure - savings rise when interest rates rise.

6 I split the data into three periods. The first break in the data is due to unstable inflation expectations prior to Q4 1997 (see Figure 3). The second break is due to the onset of the recent recession - Q4 2008 is the first quarter of negative real GDP growth.

7 A plot of money gap and inflation appears in Figure 4 in the Appendix. A correlation plot for the entire period between 1982 and 2008 appears in Figure 5 in the Appendix.

8 Prior to 1991, inflation was not the official target of monetary policy.

9 The standard deviation of the money gap is 6.32 and 5.68 in the first and the last period, respectively, in Figure 1, as opposed to 3.37 in the middle period in Figure 1. 


\section{Figure 1: Correlation between Lagged M1+ Gap and Inflation for Recent Periods}

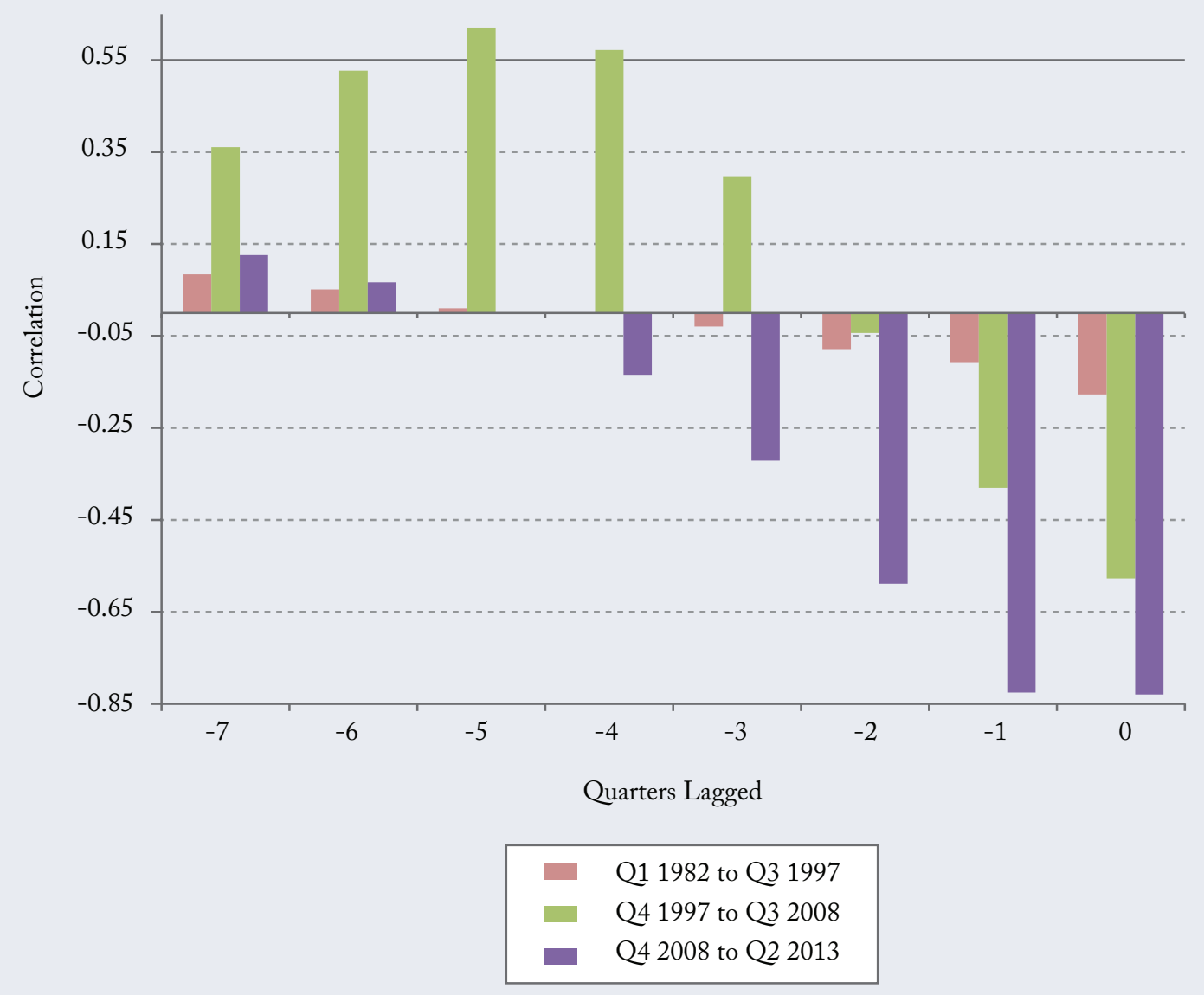

Notes: The M1+ gap is a year over year percentage growth rate of M1+ minus the year over year percentage growth rate of the nominal GDP. M1+ gap is lagged from 0 (contemporary) to 7 quarters. Inflation is a year over year percentage growth rate of the GDP Deflator. The figure presents correlation coefficients between the M1+ gap and Inflation. Quarterly data from Q1 1982 to Q2 2013.

Sources: Statistics Canada, CANSIM Tables 176-0020, 380-0064, and 380-0066.

Monetary policy affects money balances. As long as changes in money's velocity, or its growth, are predictable, the $\mathrm{BoC}$ is able to stimulate an adjustment in money balances needed to control inflation. If the growth in velocity is unpredictable, the $\mathrm{BoC}$ has a more difficult time stimulating the needed change in money balances.

The velocity of money has fallen in Canada since the early 1980s - see Figure $2 .^{10}$ The fall of the 1980 s and early 1990s likely occurred because higher computing power enabled banks to pay monthly or daily interest

10 Of course, the low interest rate environment of recent years has lowered the opportunity cost of holding cash balances - the main channel of monetary policy I discussed. This, by itself, is likely to reduce velocity. Table 1 in the Appendix, however, shows that even after controlling for the lower interest rates, velocity has been falling, as the negative significant coefficient on the time trend indicates. Velocity has been falling even faster after the recent recession - see the negative and significant coefficient on the recession dummy. This dummy takes the value of one for Q4 2008 and thereafter, and zero otherwise. 


\section{Figure 2: Velocity of M1+ in Canada}

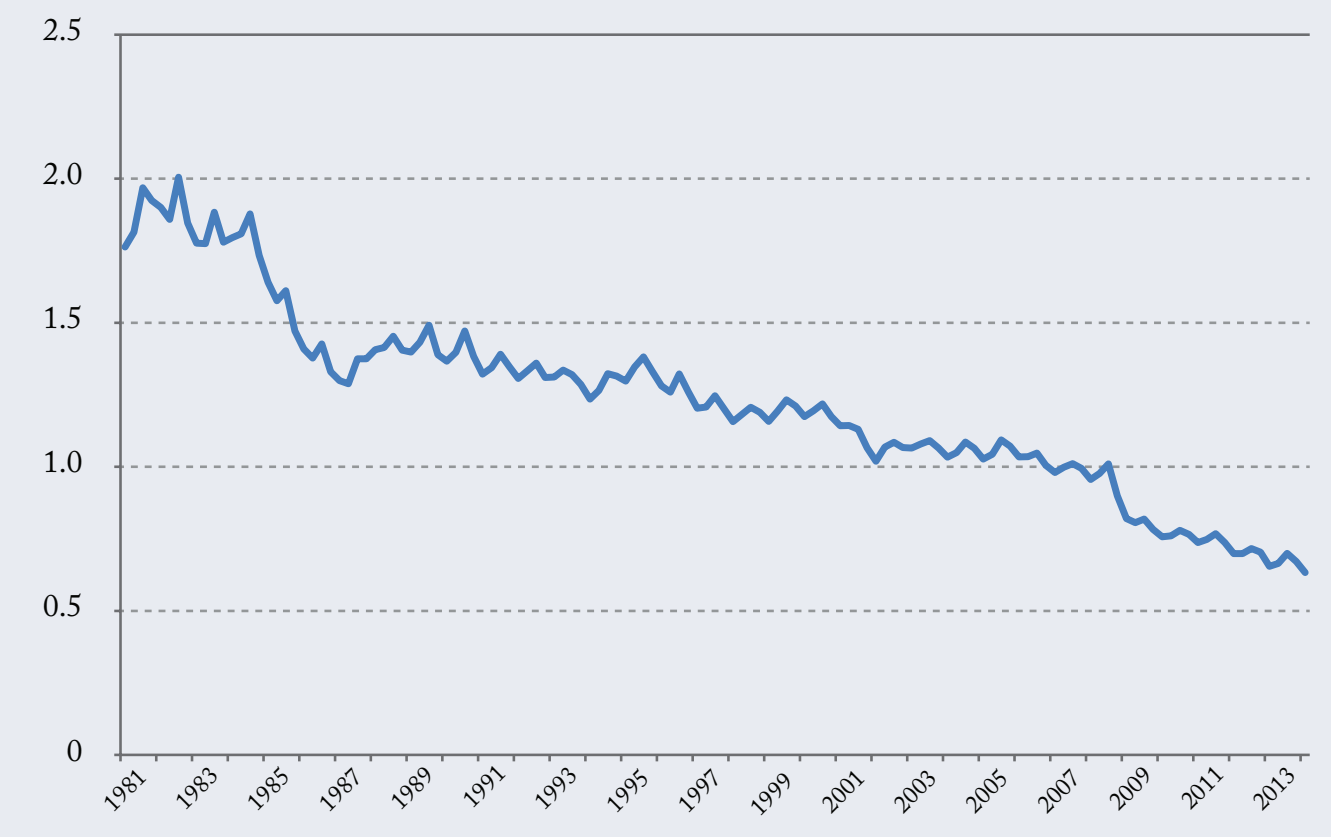

Sources: Author's calculations. Statistics Canada, CANSIM Tables 176-0020 and 380-0064.

on savings accounts (Laidler 1999). Velocity is highly variable today as well - for example, Canadian firms hold larger M1+ balances as a share of their current assets than ever before (Poschmann 2013). It is unlikely that the $\mathrm{BoC}$ could anticipate these changes ahead of time. At the same time, frequent fluctuations in the money gap and its delayed impact on inflation add more variability to inflation itself. These factors can explain why the BoC had a harder time controlling inflation in the 1980s, and more recently.

\section{What Should the Bank of Canada Do?}

My analysis thus far shows that unpredictable changes in velocity have made monetary policy in Canada less effective. If the past is an indicator, these fluctuations in velocity are transitory - predictable inflation and the stable money gap - inflation relationship persisted for a decade when velocity growth, or the money gap, changed little. For this reason, the BoC may not need to act drastically, but simply weather the turbulent times. I urge the $\mathrm{BoC}$, however, to expand its diagnostics kit.

First, the BoC should monitor monetary aggregates and report their growth - actual and forecasted. ${ }^{11}$ The strong association between the money gap and inflation during the decade of effective monetary policy - 1997

11 The BoC largely stopped monitoring monetary aggregates due to their weak relationship to inflation in the first half of the 1980s (Laidler 1999). 


\section{Figure 3: Nominal and Real-Return Bond Rates (the spread measures inflation expectations)"}

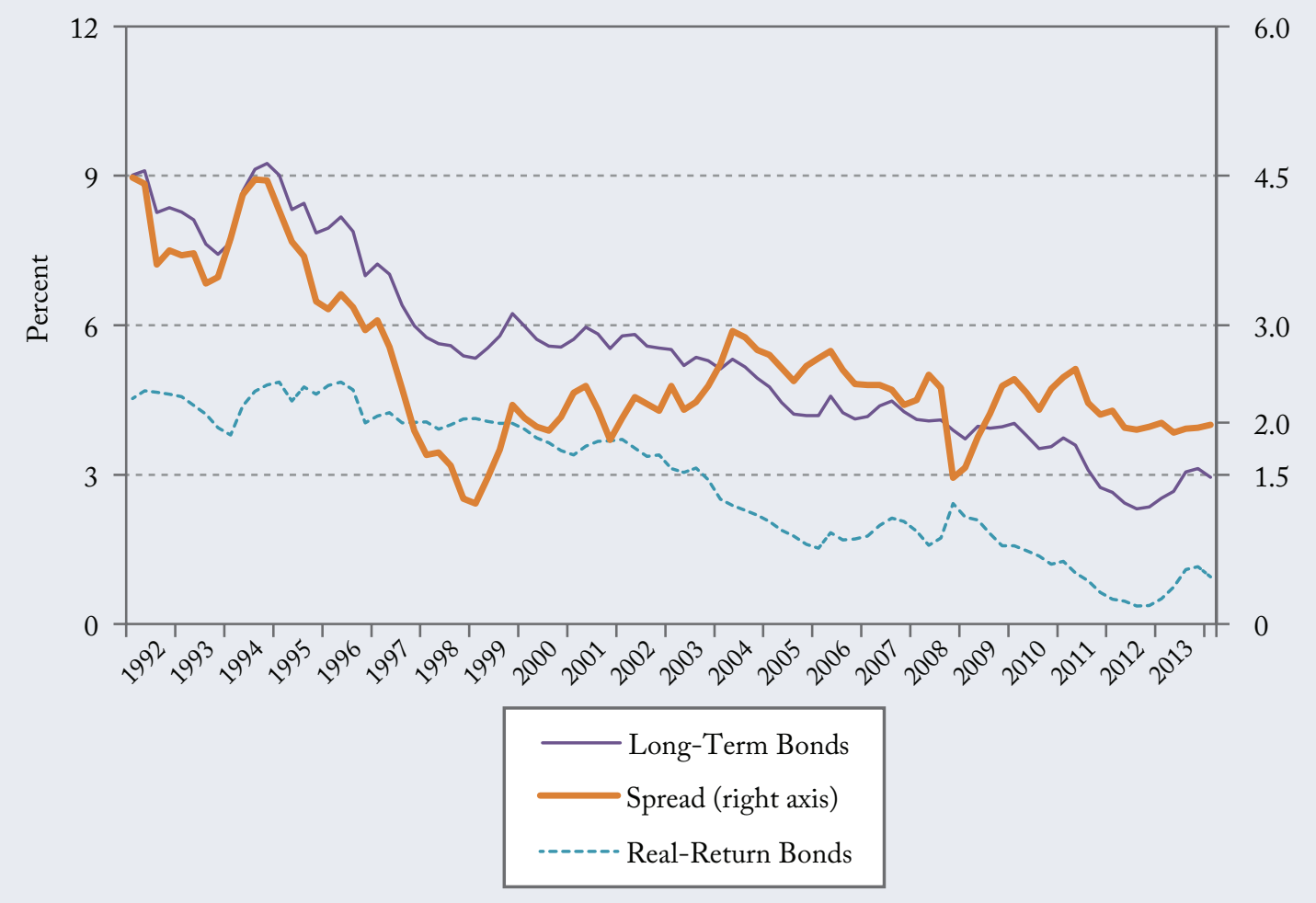

Note: The percentage data represents actual yield for the period. Data on real-return bonds is not available from CANSIM prior to Q1 1992.

Source: Statistics Canada, CANSIM Table 176-0043.

to 2008 - shows that in stable times the money gap is a good predictor of inflation. The Bank of England (BoE), the European Central Bank (ECB), and the Federal Reserve (Fed) in the US, for example, report monetary aggregates.

Second, the BoC should expand its monitoring of inflation expectations. Inflation expectations matter a lot for the decisions that Canadian firms and consumers make. Unstable inflation expectations can present even more challenges to monetary policy and actual inflation. While from late 2011 until now, inflation expectations have been stable at the 2 percent target (Figure 3), ${ }^{12}$ the monitoring must continue.

12 Real return bonds are intended to provide returns unaffected by changes in the purchasing power, while nominal bonds have coupons denominated in current dollars that lose their purchasing power over time. To compensate for the expected fall in purchasing power of the coupon payments, the price of the bond tends to decline over time, such that the yield compensates both for the expected inflation and the return forgone by not investing somewhere else in the economy. Real return bonds do only the latter. Thus, the spread between nominal and real return bonds is a measure of market compensation due to loss of future purchasing power - expected inflation (Laidler and Robson 2003). 
The BoC includes in its reports surveys of business inflation expectations as well as its own forecasts, and I recommend expanding this practice. A survey of professional forecasters - experts affiliated with financial and non-financial institutions, ${ }^{13}$ and a survey of households might complete the picture. As the EU and the US experiences show, both surveys have the potential to provide useful information (Garcia 2003, Mestre 2007, Coibion and Gorodnichenko 2013).

If and when the BoC finds that inflation expectations fall below target, based on various measures, it should ease the overnight rate or pursue a quantitative easing strategy, by directly injecting money into the economy. From what we know, these measures are not necessary at this point, but it is better to be safe by monitoring expectations more explicitly, than sorry later.

\section{Conclusion}

Monetarist approaches, as reflected in the seminal publications on the topic (Laidler 1999, Laidler and Robson 1991), offer a method of examining the effectiveness of monetary policy. By this standard, the effectiveness of monetary policy was at its highest during the period from the late 1990s through most of the 2000s. Since 2008, monetary policy seems to have been less effective, and exhibits a weaker relationship to inflation - similar to the 1980s and early 1990s. The reason behind both is likely similar - unpredictable changes in the velocity of money.

I find no immediate reasons for concern, as inflation expectations - the driver of firm and household behaviour - have been near their target of 2 percent in the past two years. However, there is a danger of lowered inflation expectations, which would have an adverse effect on the Canadian economy.

I urge the $\mathrm{BoC}$ to monitor both the monetary aggregates and inflation expectations more closely. Household surveys of inflation expectations will provide a useful addition to current measures. The BoC needs to be prepared to shift gears appropriately if expectations appear to deviate from the 2 percent target.

13 Presumably, professional forecasters also answer the business outlook surveys. It may be useful, however, to separate the opinions of professional forecasters from others. 


\section{Appendix}

\section{Empirical Analysis of the Velocity of Money in Canada}

It is interesting to establish whether the velocity of money in Canada has fallen since the recent recession beyond what low interest rates and a time trend can explain, as this would imply a fall that was difficult to predict.

I model velocity as determined by the bank rate, a time trend, and a recession dummy which equals one for Q4 2008 and thereafter, and zero otherwise. Conceptually, the velocity of a monetary aggregate depends on nominal GDP and the demand for money balances, among other variables. In practical applications, however, the ratio of the two measures velocity itself, hence, nominal GDP and money balances cannot enter the empirical specification.

Due to an auto-correlated time series structure of the data, I include a one period (quarter) lagged dependent variable, and use the Newey-West auto-correlation robust estimator for standard errors. Finally, for convenience, I scale the dependent variable by ten thousand. This procedure does not affect the significance or the sign of the coefficients, however, it makes them easier to read. The results are in Table 1 . The negative and significant coefficients on the recession dummy in specifications (3) and (4) suggest a fall in velocity beyond the trend of previous years, and beyond what the low interest rates can explain.

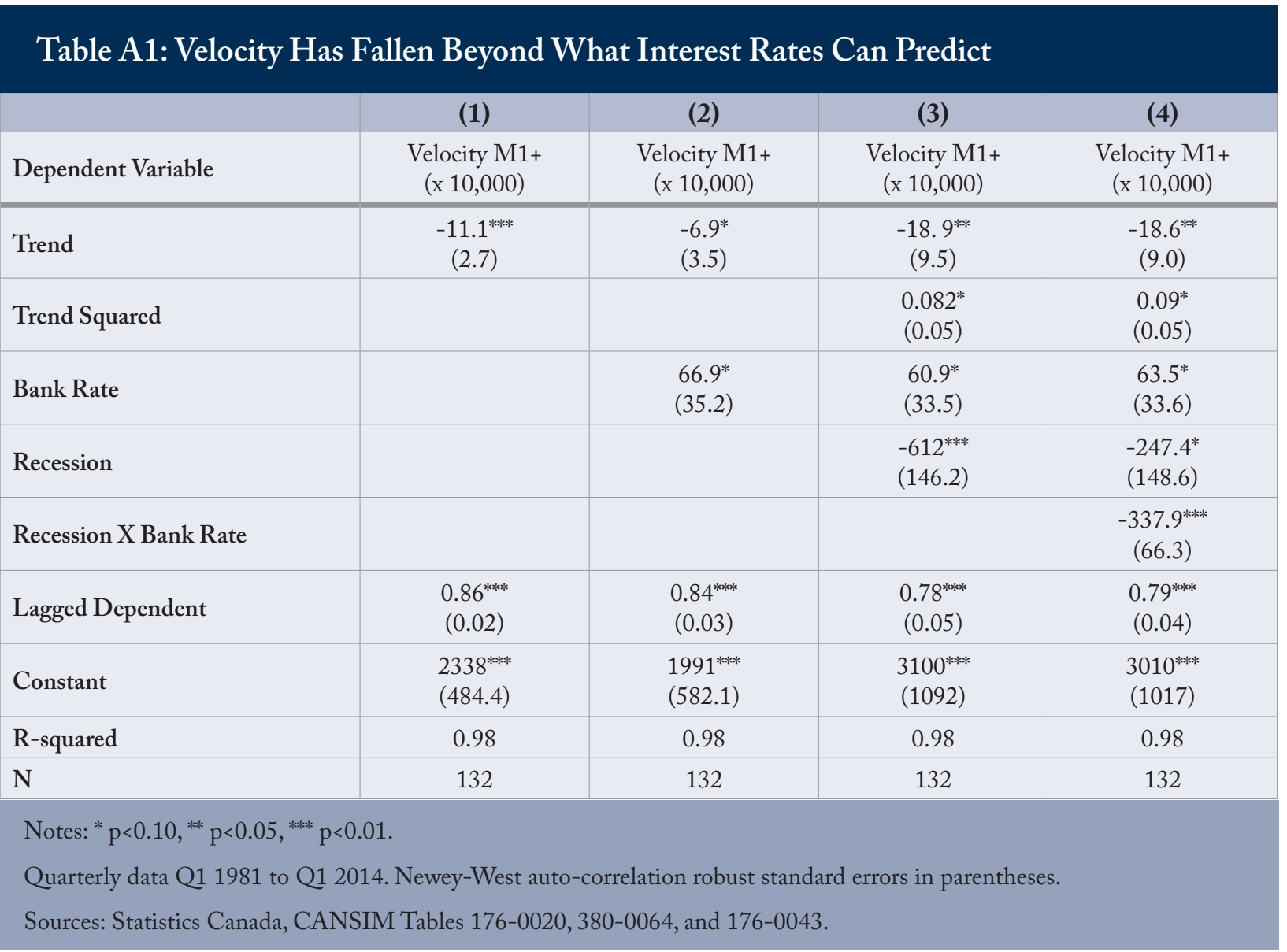




\section{Figure A1: Money Gap and Inflation}

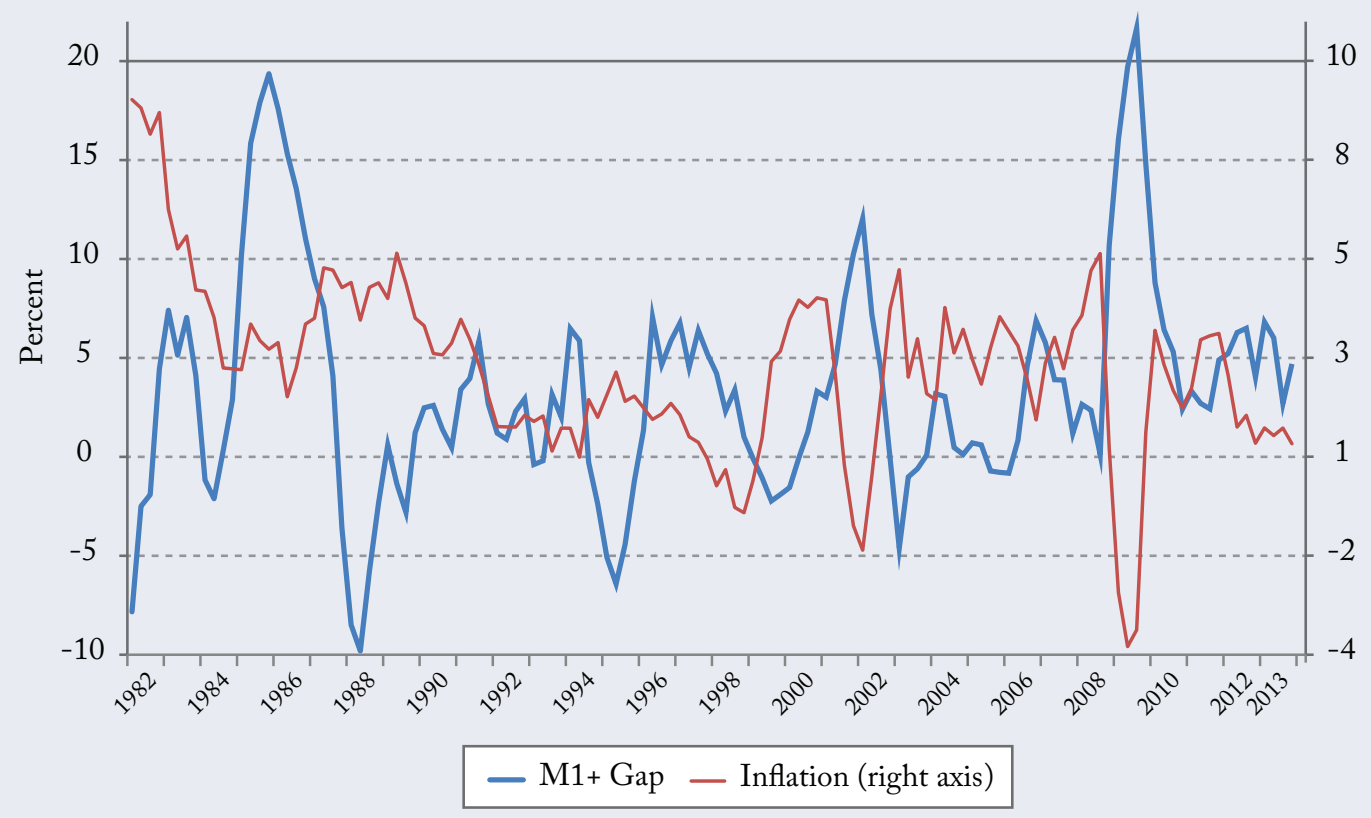

Notes: The M1+ gap is a year-over-year percentage growth rate of M1+ minus the year-over-year percentage growth rates of nominal GDP. Inflation is year-over-year percentage growth rate of the GDP Deflator. Quarterly data from Q1 1982 to Q4 2013.

Sources: Statistics Canada, CANSIM Tables 176-0020, 380-0064, and 380-0066. 
Figure A2: Correlation between Lagged M1+ Gap and Inflation from 1982 and until the Third Quarter 2008 (recent recession)

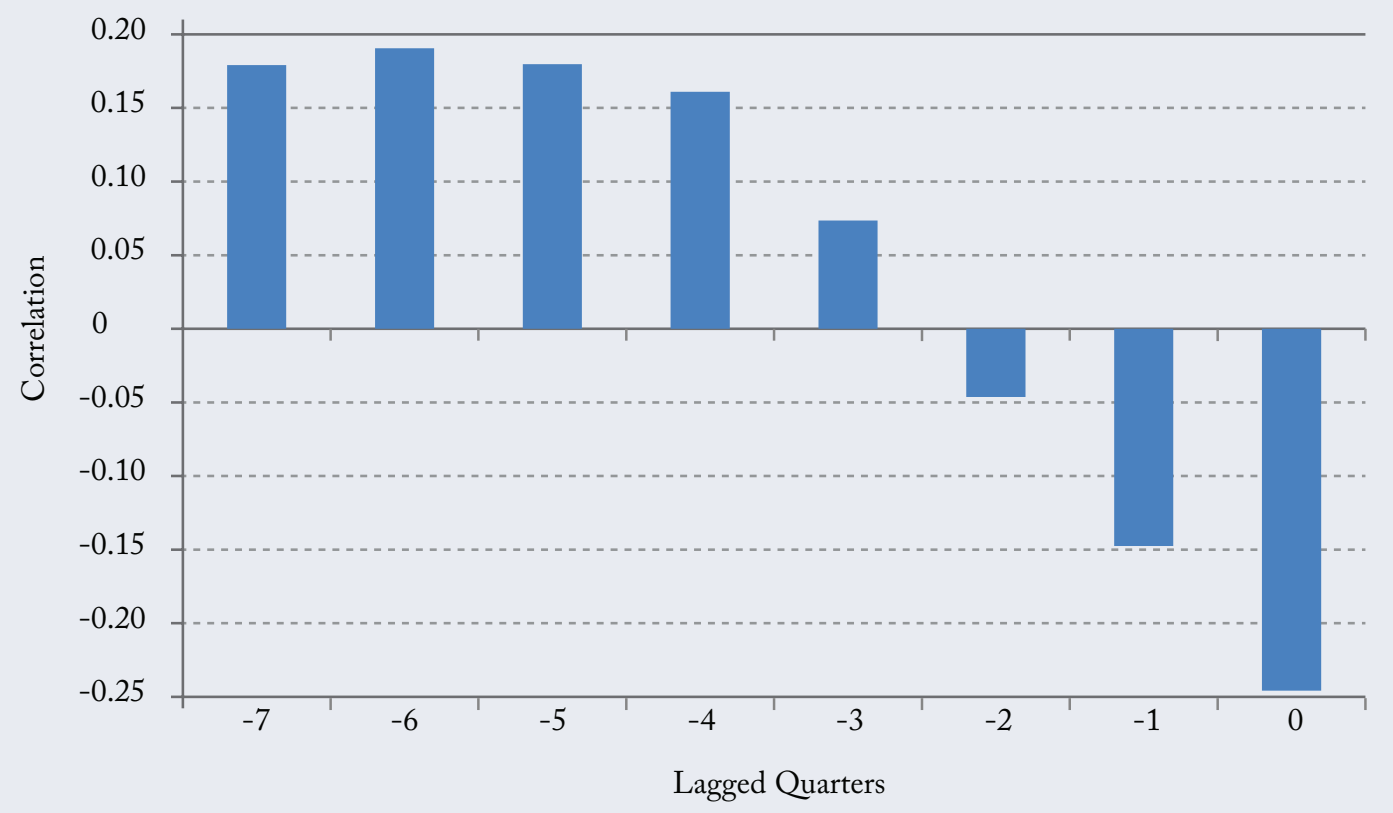

Notes: The M1+ gap is a year-over-year percentage growth rates of M1+ minus the year-over-year percentage growth rates of the nominal GDP. Inflation is year-over-year percentage growth rate of the GDP Deflator. Quarterly data from Q1 1982 to Q3 2008.

Sources: Statistics Canada, CANSIM Tables 176-0020, 380-0064 and 380-0066. 


\section{References}

Bank of Canada. 2011. "Canada’s Money Supply." Backgrounders. October. Available at: (http://www. bankofcanada.ca/wp-content/uploads/2010/11/canada_money_supply.pdf)

.2012. "How Monetary Policy Works: The Transmission of Monetary Policy."

Backgrounders. April. Available at: (http://www.bankofcanada.ca/wp-content/uploads/2010/11/how_ monetary_policy_works.pdf)

Coibion, Olivier, and Yuriy Gorodnichenko. 2013. "Is The Phillips Curve Alive and Well After All? Inflation Expectations and the Missing Disinflation.” Mimeo. UC Berkeley. (http://eml.berkeley. edu/ ygorodni/CG_missing_disinflation.pdf)

Freedman, Charles. 2000. "Monetary Policy Implementation: Past, Present and Future - Will Electronic Money Lead to the Eventual Demise of Central Banking?" International Finance-Oxford, 3(2): 211-228.

Garcia, Juan Angel. 2003. “An Introduction to the ECB's Survey of Professional Forecasters.” Occasional Paper Series No. 8. European Central Bank. September. Available at: (https://www.ecb.europa.eu/ pub/pdf/scpops/ecbocp8.pdf)

Laidler, David. 1999. “The Quantity of Money and Monetary Policy.” Working Paper 99-5. Bank of Canada. April. Available at: (http://www.banqueducanada.ca/wp-content/uploads/2010/05/wp99-5.pdf)

Laidler, David, and W. B. P. Robson. 1991. Money Talks - Let's Listen. Commentary 26. Toronto: C.D. Howe Institute. January.

2003. "No Excuse for Inaction: Inflation, Special Factors and the Case for Raising Interest Rates.” Backgrounder 71. Toronto: C.D. Howe Institute. February.

Mestre, Ricardo. 2007. “Are Survey-Based Inflation Expectations in the Euro Area Informative?” Working Paper Series No. 721. European Central Bank. February. Available at: (https://www.ecb.europa.eu/ pub/pdf/scpwps/ecbwp721.pdf)

Poloz, Stephen S. 2014. “Release of the Monetary Policy Report: Opening Statement.”July 16. http:// www.bankofcanada.ca/2014/07/opening-statement-16-07-2014/

Poschmann, Finn. 2013. "Not Dead Yet: The Changing Role of Cash on Corporate Balance Sheets." E-Brief. Toronto: C.D. Howe Institute. January.

This E-Brief is a publication of the C.D. Howe Institute.

Mati Dubrovinsky is a Senior Policy Analyst at the C.D. Howe Institute.

This E-Brief is available at www.cdhowe.org.

Permission is granted to reprint this text if the content is not altered and proper attribution is provided. 